\title{
Psychopharmacological Treatment and Psychological Interventions in Irritable Bowel Syndrome
}

\author{
Emanuele Sinagra, Claudia Romano, and Mario Cottone \\ Division of Internal Medicine "Villa Sofia-V. Cervello" Hospital, University of Palermo, Via Trabucco 180, 90146 Palermo, Italy \\ Correspondence should be addressed to Emanuele Sinagra, emanuelesinagra83@googlemail.com
}

Received 20 March 2012; Revised 28 May 2012; Accepted 4 July 2012

Academic Editor: Giovanni Barbara

Copyright (C) 2012 Emanuele Sinagra et al. This is an open access article distributed under the Creative Commons Attribution License, which permits unrestricted use, distribution, and reproduction in any medium, provided the original work is properly cited.

Irritable bowel syndrome (IBS) accounts for 25\% of gastroenterology output practice, making it one of the most common disorders in this practice. Psychological and social factors may affect the development of this chronic disorder. Furthermore, psychiatric symptoms and psychiatric diseases are highly prevalent in this condition, but the approach to treating these is not always straightforward. As emphasized in the biopsychosocial model of IBS, with regard to the modulatory role of stress-related brain-gut interactions and association of the disease with psychological factors and emotional state, it proves useful to encourage psychopharmacological treatments and psychosocial therapies, both aiming at reducing stress perception. The aim of this paper is to analyze the effectiveness of psychopharmacological treatment and psychological interventions on irritable bowel syndrome.

\section{Introduction}

Irritable bowel syndrome (IBS) is a chronic, relapsing, and remitting functional disorder of the gastrointestinal (GI) tract for which there is no known structural or anatomical explanation.

Its prevalence in the general population is estimated to be between $5 \%$ and $20 \%$ [1-4], accounting for up to $25 \%$ of gastroenterology output practice [5]. The presence of IBS is defined by clinical criteria, which include the presence of abdominal pain, or discomfort, and alterations in bowel habits, in the absence of red flag alarm features, such as weight loss or anemia [6].

IBS is defined by the Rome III criteria as "symptoms of recurrent abdominal pain or discomfort and a marked change in bowel habits for at least six months, with symptoms experienced on at least three days of at least three months, with two of the three following findings: (a) pain is relieved by a bowel movement; (b) onset of pain is related to a change in frequency of stool; (c) onset of pain is related to a change in appearance of stool" [7].

The cause of IBS is actually unknown, but probably it is unlikely that a single factor is responsible for the diverse presentations of this heterogeneous and complex disorder.
In fact, IBS has a multifactorial etiology, involving altered gut reactivity and motility, altered pain perception, and alteration of the brain-gut axis [8]. In addition, psychological and social factors can influence digestive function, symptom perception, illness behavior, and outcome [9]. According to the biopsychosocial model of IBS, symptoms are both determined and modified by psychological and social influences, and the link between psychosocial factors and GI functions is through the brain-gut axis $[10,11]$.

The brain-gut axis allows bidirectional input and thus links emotional and cognitive centers of the brain with peripheral functioning of the GI tract and vice versa. Hence extrinsic (vision, smell, etc.) or enteroceptive (emotion, thought) information has, by nature of its neural connections from higher centers, the capacity to affect GI sensation, motility, secretion, and inflammation. Conversely, viscerotropic effects (e.g., visceral afferent communications to the brain) reciprocally affect central pain perception, mood, and behavior [12].

Since the biopsychosocial model of IBS was developed, there has been constantly growing interest in the influence of psychosocial factors on the pathogenesis and clinical course of IBS [8]. 
Psychological and social factors may already affect the development of IBS early in life, conditioning one's psychosocial development, and during life, leading to gut dysfunction and dysregulation of the brain-gut axis, through the alteration of digestive functions (motility, sensation, inflammation), symptom perception, and illness behavior [11].

Studies about IBS clustering in families show that environmental factors may play a role, together with inherited mechanisms, in the development of IBS [13, 14]. A history of abuse represents a particularly important factor leading to increased psychological distress [15-21].

Personality traits are also implicated in the pathogenesis of IBS and in the decision to seek medical help [8]. Neuroticism (considered as the tendency to experience negative emotions) and alexithymia (defined as difficulty in identifying feelings and distinguishing between feelings and bodily sensations) are the most prevalent traits; furthermore, neuroticism is a predictor of illness perception and influences coping strategies [22-25].

Furthermore, patients with IBS often present irrational health beliefs, leading to hypochondriac attitudes and respond to their illness adopting different coping strategies, compared with patients with organic diseases or healthy controls [26-28].

Finally, psychiatric symptoms and psychiatric diseases are frequent in IBS, especially in severe forms. Conversely, patients with severe IBS may have more than one psychiatric disorder [29-32]. Particularly, depression is the most common psychiatric disorder in IBS, involving approximately $30 \%$ of patients. In this subset of patients, high levels of somatization determine frequent use of health care services, poor response to treatment and poor health-related quality of life [28, 33-38].

As emphasized in the biopsychosocial model of IBS, with regard to the modulatory role of stress-related brain-gut interactions and its association with psychological factors and emotional state, it proves useful to encourage psychopharmacological treatments and psychosocial therapies, both aiming at reducing stress perception. The aim of this paper is to analyze the effectiveness of psychopharmacological treatment and psychological actions on irritable bowel syndrome.

Figure 1 shows schematically the targets of currents and new psychopharmacological therapies for IBS.

\section{Antidepressants}

Among the currently available classes of drugs for the treatment of IBS, antidepressants are useful because of their analgesic properties, independent of their mood-improving effects, and they may therefore be beneficial to patients with neuropathic pain [39-42].

Long-term use of all antidepressants makes it possible to enhance glucocorticoid signaling and to inhibit overactivity of corticotrophin-releasing factors in the brain and presumably in the periphery. Each class of antidepressants affects several transmitters via reciprocal actions between amine and neuropeptide systems and reduces excessive cytokine release associated with various conditions in which inflammatory cytokines play a role [43].

Antidepressants alter receptor sensitivity, which in all cases is believed to result in enhanced serotonin neurotransmission. In particular, tricyclic antidepressants (TCADs) increase the sensitivity of postsynaptic serotonin receptors and downregulate alpha- 2 presynaptic receptors and heteroreceptors; their analgesic effects are also mediated by blockage of a class of voltage-dependent sodium channels in extrinsic sensory neurons [44]. They also antagonize muscarinic acetylcholine receptors [45]. These antimuscarinic effects of TCADs are responsible for many of their side effects, including constipation, dry mouth, and blurred vision [46]. However, slowing of GI transit may be of therapeutic advantage in diarrhea-predominant IBS [47]. In contrast, selective serotonin reuptake inhibitors (SSRIs) and serotonin-norepinephrine reuptake inhibitors (SNRIs) reduce the sensitivity of 5HT-1A autoreceptors and heteroceceptors, whose downregulation is believed to play the most important role in the antidepressant, anxiolytic, and analgesic effects of antidepressants. In this connection, serotonin acts as a secretagogue and tends to stimulate GI motility [46]. Thus, SSRIs could be particularly useful in patients with constipation-predominant IBS [6].

A 2009 meta-analysis that included 13 placebocontrolled trials of antidepressants in 789 adults with IBS concluded that antidepressants were significantly more effective than a placebo for the relief of pain and global symptoms (relative risk of IBS symptoms persisting 0.66, $95 \%$ CI 0.57 to 0.78 ) at a duration of therapy ranging from one to three months [47]. The number needed to treat one patient was four. The treatment effects were similar for SSRIs and TCADs. A similar conclusion was reached in a 2009 position statement from the American College of Gastroenterology Task Force on IBS [48].

Three further RCTs have been published since the metaanalysis was published, but the results were conflicting, with two demonstrating a benefit of TCADs and SSRIs $[49,50]$ and a third demonstrating no benefit of SSRIs [51]. However, when the results of these trials are incorporated into the prior meta-analysis, the benefit of both TCADs and SSRIs remains reassuringly similar [52].

A systematic review performed by the Cochrane Library, and evaluating bulking agents, antispasmodics, and antidepressants for the treatment of IBS (but without considering the safety of these drugs), emphasized that "antidepressants are effective for the treatment of IBS" [53], providing a statistically significant benefit over placebo for abdominal pain, global assessment and IBS-symptoms score. Subgroup analyses for SSRIs and TCADs showed a statistically significant improvement in global assessment for SSRIs and a statistically significant improvement in abdominal pain and symptoms score for TCADs. The authors concluded that antidepressants could be used in patients who seek drug therapy and who have not responded to antispasmodics, but considering that their effectiveness may vary with individual patient features. 


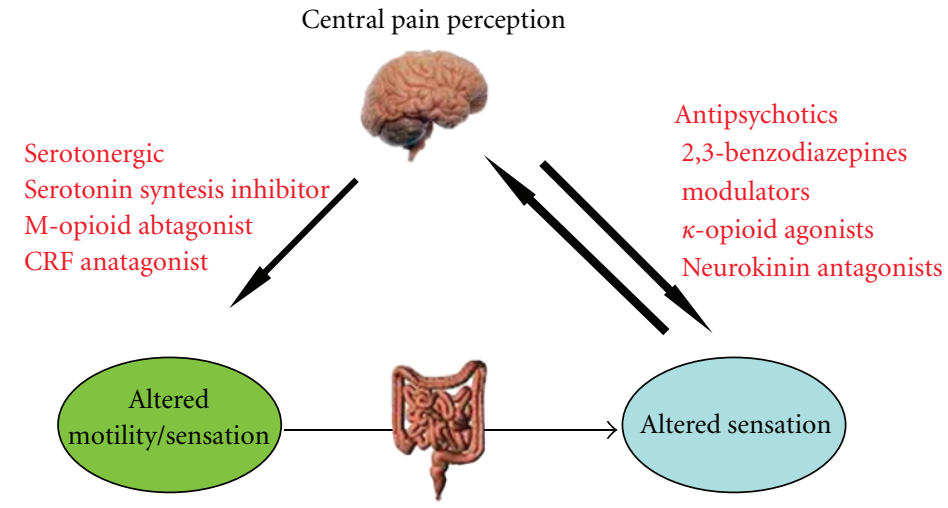

FIGURE 1: Brain-gut axis and pharmacological approaches for irritable bowel syndrome. This figure shows schematically the targets of the current and novel psychopharmacological therapies for irritable bowel syndrome. The reason to use these approaches is the presence of bidirectional connections between brain and gut: according to this pathophysiological model, emotional and cognitive centers of the brain, particularly those involving pain perception, are linked with peripheral functioning of gastrointestinal tract, and vice versa, thus, conditioning intestinal motility, sensation, and inflammation.

With regard to the practical use of antidepressants in IBS, improvement in neuropathic pain with TCADs occurs at lower doses than required for treatment of depression. The initial doses of the drugs should be administered, as a result, at a low dosage, titrating them to pain control and tolerance.

In case of partial response to treatment, it is prudent to increase the dose of the drug, reassessing response and tolerability every 4-6 weeks. With an adequate dosage, some response in the first 6-8 weeks should be apparent, but remission can occur. If there is no response at 6 weeks, and compliance and treatment intensity appear to be adequate, switching to another class may obviate the need for referral for psychiatric consultation. Whether to persist or refer remains a clinical decision between the physician and patient. For some patients, the use of concomitant benzodiazepines for anxiety control may help with compliance and allows more optimal control of symptoms [54].

In contrast, antidepressant efficacy is unproven in children, as illustrated in a multicenter trial of 83 children with functional GI disorders, in which they were randomly assigned to amitriptyline or a placebo for four weeks, considering, as the primary end-point, the child's assessment of pain relief and sense of improvement [55]. At four weeks, there was no significant difference between amitriptyline and the placebo in the frequency of attaining the primary endpoint (63 versus 58 percent, $P=0.85$ ). The authors also noted that a longer period of treatment and a higher dose of antidepressants may have produced different results and that there may be a large placebo effect in children due to multiple factors; indeed, in another trial of 33 adolescents assigned to amitriptyline or a placebo, the first one was effective in reducing diarrhea and pain after a longer period of treatment [56].

This finding is also emphasized in the review performed by the Cochrane Library, where the authors conclude that clinicians must be aware that the existing randomized controlled evidence is limited to studies on amitriptyline and revealed no statistically significant difference between amitriptyline and a placebo for most efficacy outcomes in children and adolescents. Furthermore, antidepressants can lead to substantial, sometimes life-threatening adverse effects, and consequently, until better evidence evolves, clinicians should weigh up the potential benefits of antidepressants in pediatric patients [57].

Although standard antidepressants of the tricyclic and serotonin reuptake inhibitors classes have been assessed in meta-analyses, as mentioned above, an example of a novel class of centrally acting agents that has not been assessed extensively is the atypical antipsychotic quetiapine, which ameliorates anxiety and sleep disturbances, augments the effect of antidepressants, and provides an independent analgesic effect [58].

The use of atypical antipsychotics could be considered in the setting of patients with severe IBS and coexistent severe psychiatric comorbidity. In this connection, in a study on the medical data of patients with severe refractory GI disorders, Grover et al. [59] reported that, among the 11 of 21 patients still on the medication at followup, 6 demonstrated global relief of symptoms and 9 were satisfied with treatment. The other 10 patients discontinued therapy because of the drug's side effect of somnolence or because of lack of GI efficacy. This is a very specific group of patients with known and significant psychiatric diagnoses. This approach requires further blind studies before it can be endorsed; physicians without experience with this class of agents should probably avoid prescribing them [58]. As a consequence, one should not recommend its use until the evidence yields solid data regarding the efficacy and safety of this class of drugs.

\section{Benzodiazepines}

Benzodiazepines enhance the inhibitory effects of gammaaminobutyric acid (GABA) via potentiation at the GABA-A receptors, diminish norepinephrine neurotransmission, and antagonize the effects of cholecystokinin in the brain and gut. This results in immediate anxiolytic activity [45]. 
Patients with prominent anxiety are often intolerant of antidepressants and can be treated with benzodiazepine monotherapy [54].

Benzodiazepines receptors were identified in subcortical and hypothalamic regions and appear important in controlling autonomic functions [53], such as motor and sensory activity of the gut [60]: nevertheless they do not exist in the gut [61]. Furthermore, benzodiazepines may lower pain thresholds by stimulating GABA, thereby decreasing brain serotonin. Animal studies on the R-enantiomer of tofisopam (the nonsedative anxiolytic), dextofisopam, showed encouraging results in reducing colon motility and visceral sensitivity with little effect beneath basal conditions [62].

In a phase IIb study of dextofisopam for 12 weeks in 140 patients with IBS, Leventer et al. observed overall symptom relief (primary end point) in 57\% of patients as compared with placebo (43\% of patients). Although dextofisopam improved stool consistency in men and women, the recurrence rate was only decreased in females. This occurred within one week. The most common side effects were headache and abdominal pain (in $12 \%$ of patients in comparison with $4 \%$ in the placebo group) which were comparable to placebo. No benefit on bloating, partial defecation, or hospital anxiety and depression scale scores was observed [63].

The main disadvantage of benzodiazepines is the lack of reliable antidepressant efficacy, even if in open-label studies, alprazolam (2-8 mg/day) improves IBS in patients with panic disorders [64]. In another study, Castedal et al. [65] showed a slight effect of midazolam on small bowel motility using manometry; however, phase III related retroperistalsis did not work.

Anxiolytic agents are of limited usefulness in IBS because of the risk of drug interactions, tolerance, potential abuse, and rebound withdrawal. They may, however, be useful for short-term reduction of acute situational anxiety that may be contributing to symptoms [46].

\section{Future Psychopharmacological Perspectives}

On the basis of the results of the clinical trials confirming the effectiveness of centrally-targeted pharmacological interventions, such as with antidepressants, anxiolytics, or a combination of both groups in the treatment of IBS, many other pharmacological agents with similar anxiolytic and/or antidepressant properties have recently been shown to modulate stress-induced visceral hyperalgesia in animal models [66]. Among these agents, opioidergic agents, cannabinoid receptor 1 (CB1), beta-3 adrenergic and somatostatin receptors agonists, N-methyl-D-aspartate (NMDA), CRF1 and cholecystokinin receptor antagonists give encouraging results.

As visceral hypersensitivity is a proposed etiological factor in IBS, as mentioned above, one way to improve a sufferer's symptom might be to modulate pain receptors in the GI tract. Pregabalin and gabapentin, drugs believed to inhibit pain via the alpha-2-deta-subunits of voltage gated calcium channels, have both been studied in small singlecenter RCTs $[67,68]$. Pregabalin was more effective than a placebo, in terms of increasing the sensory thresholds for perception of rectal distension, desire to defecate, and rectal pain, and also demonstrated a trend towards an improvement in average daily pain scores during 3 weeks of therapy [67]. Patients treated with gabapentin demonstrated significantly increased rectal compliance, as well as higher sensory thresholds for bloating, discomfort, and pain during a 5-day treatment period [68].

The efficacy of agonists to the kappa-opioid receptors has also been studied in IBS. After a 100-mg intravenous infusion of fedotozine, thresholds to first perception of colonic distension and pain were significantly increased compared with placebo [69]. A single dose of asimadoline led to an increased pain threshold to colonic distension and significantly reduced the area under the curve of pain intensity in a crossover RCT conducted in 20 IBS subjects [70]. However, further large RCTs of the latter drug have been disappointing $[71,72]$. One RCT demonstrated no difference in achievement of the primary end-point, average reduction in pain severity 2 hours after treatment, between asimadoline and a placebo [72], although in a post-hoc analysis there appeared to be a benefit in those with an alternating bowel habit. The second study, conducted in almost 600 IBS patients, also failed to demonstrate any superiority of the drug over a placebo when the proportion of months with adequate relief of IBS pain or discomfort was the primary outcome (37\% with active drug versus 33\% with placebo) [71]. In contrast to the study by Szarka and colleagues, when a preplanned subgroup analysis was conducted, the drug appeared significantly more effective than a placebo only in IBS-D patients ( $47 \%$ versus $20 \%$ ).

On the other hand, solabegron, a beta- 3 adrenergic agonist, was proposed as a treatment for IBS, based on the finding of functional beta- 3 adrenergic receptors on enteric neurons [73]. However, solabegron failed to show any significant effect on human gastrointestinal or colonic transit [74]. A preliminary report of a clinical trial showed that solabegron, $200 \mathrm{mg}$ b.i.d., led to a statistically significant increase in the proportion of female subjects $(P=0.019)$ and possibly subjects of both genders $(P=0.06)$ achieving adequate relief from IBS-related pain and discomfort, as compared with a placebo. There were also improvements in pain scores and the number of pain-free days but (consistent with transit results) no significant changes in bowel symptoms [75].

NMDA receptors are involved in the induction and maintenance of central sensitization during pain states and may also medicate peripheral sensitization and visceral pain. NMDA receptors are composed of NR1, NR2 (A, B, C and $D$ ), and NR3 (A and B) subunits, which determine the functional properties of native NMDA receptors. Among NMDA receptor subtypes, the ones containing the NR2B subunit appear particularly important for nociception, thereby, suggesting that NR2B-selective antagonists may be useful in the treatment of chronic pain syndromes $[58,76]$.

Dextromethorphan is a noncompetitive NMDA receptor antagonist that is widely used as an antitussive agent. 
In studies conducted on animals, it has been shown to prevent neuronal damage and modulate pain sensation via noncompetitive antagonism of excitatory amino acids. It has proved useful in the treatment of pain in patients with cancer [77]. Somatic heat hyperalgesia has been reported to be associated with increased intestinal permeability in patients with IBS [78]. A subset of IBS patients, but not controls, showed temporal summation of pain in response to a series of six noxious heat pulses. In this setting, perceived intensity of second pain (wind-up) markedly increases with each successive heat pulse. IBS patients who demonstrated temporal summation of pain received $60 \mathrm{mg}$ of dextromethorphan or $50 \mathrm{mg}$ of benadryl in a randomized, doubleblind fashion to block wind-up pain. Temporal summation of pain was blocked more effectively by dextromethorphan, an NMDA receptor antagonist, than by benadryl [79].

Regarding the efficacy of cholecystokinin receptor antagonist, the effect of dexloxiglumide, a CCK-1 receptor antagonist, has been studied in female IBS-C patients [80]. However, the drug had no overall effect on colonic transit time. Despite this, the proportion of patients with satisfactory relief of their IBS symptoms was higher with dexloxiglumide than with a placebo (39\% versus $11 \%)$, although this difference was not statistically significant.

Similarly, pexacerfont, a CRF-1 receptor antagonist, has been evaluated in women with IBS-D [81]. This drug had no effect on orocecal transit time, stool frequency or consistency, or subjective IBS symptoms, including pain and bloating.

Lastly, a study investigating the effect of a slow-release preparation of octreotide on rectal sensitivity and symptoms in IBS patients, although showing an increased threshold of first rectal sensation and improved stool consistency, highlighted the fact that long-term treatment with this agent had no visceral analgesic effect and failed to improve IBS symptoms [82].

In Tables 1 and 2 are showed, respectively, current and novel psychopharmacological approaches for the treatment of IBS.

\section{Psychological Interventions}

Although the etiology of IBS has not been elucidated completely, it is widely accepted that this entity is multifactorial, with external stress and environmental factors playing some role [83]. Since treatment with diet or pharmacological agents alone has been partially successful, psychological interventions have been instituted with promising efficacy. [84].

A broad range of evidence-based mind-body interventions including psychodynamic therapy, cognitivebehavioral therapy (CBT), hypnotherapy, relaxation exercises, or mindfulness meditation has been shown to amend stress coping strategies, both at a cognitive level (catastrophic or self-defeating thoughts) and at a behavioral level (problem solving, especially interpersonal problems) $[85,86]$. The symptomatic improvement appears to result from the modulation of stress response, autonomic nervous system balance restoration, and changes in the brain activation pattern in response to visceral stimuli [87].

Interestingly, the symptom course and relapse pattern after psychotherapy seem to differ from those after drug treatment [88]. In one trial, 101 IBS patients received standard medical therapy with or without psychotherapy administered over a 3-month period [89]. During the 3month intervention period, the improvement was greater in the psychotherapy group than that in the control group. Subsequently, in a 1-year treatment-free followup, the improvement continued in the psychotherapy group, whereas symptoms recurred in the controls, who returned to their initial state [89].

With regard to different psychotherapy approaches, more than 22 trials have been published [47, 90], substantially demonstrating that psychotherapy not only improves psychological symptoms (as anxiety and depression), but also GI symptoms directly [91]. Many of these studies were, however, not selected for meta-analysis because of specific difficulty in controlling unspecific effects. A true "placebo treatment" for such studies is not available and waiting list controls, a frequently established mode in psychotherapy research, may be inappropriate for meta-analytic purposes.

Considering these difficulties, Ford and coworkers, in their meta-analysis mentioned above, observed that while antidepressants are effective in the treatment of IBS, there are few high-quality studies on the use of psychological therapies in IBS; nevertheless, they showed that a range of different psychological therapies was able to significantly reduce physical symptoms in patients with IBS, with studies on CBT providing the greatest evidence [47].

Similarly, in another systematic review and meta-analysis performed by the Cochrane Library [90], the authors concluded that psychological therapies may be superior to the usual care at the end of treatment, although the clinical significance of this benefit is doubtful, considering that the results of the meta-analysis should be interpreted with caution, due to the low methodological quality of the studies included, variability in outcome definitions and small sample size, which resulted in considerable heterogeneity.

According to the authors, psychological therapies in general are not superior to placebos, and the long-term sustainability of the treatment effects of psychological therapies is questionable [90].

In this situation, self-managed support is challenging. A recent systematic review performed by Dorn about self-management support interventions for IBS, including eleven studies, emphasizes the fact that self-management is an essential component of care for IBS [92]. It requires providers to help their patients understand their conditions, manage their own medications, deal with emotional sequelae, develop problem-solving skills, and learn how to find and utilize resources. However, many studies included in this review were of subpar quality, and most of the interventions did not seem feasible for "real world" clinical practice, suggesting that the key challenge for improving selfmanagement in IBS is to develop practical self-management interventions that can be applied across various clinical 
TABLE 1: Current psychotropic drugs used for treatment of irritable bowel syndrome.

\begin{tabular}{lll}
\hline Classes of drugs & Mechanism of action & Therapeutic issues \\
\hline Antidepressants (SSRIs, TCADs, SNRIs) & Neurotransmitters reuptake inhibitors & $\begin{array}{l}\text { Reduction of abdominal pain; limited data about } \\
\text { safety and tolerability } \\
\text { Benzodiazepines }\end{array}$ \\
Etypical Antipsychotics (Quetiapine) & $\begin{array}{l}\text { Receptorial antagonism with dopamin- } \\
\text { ergic (D2) and serotoninergic (5-HT2) } \\
\text { receptors }\end{array}$ & $\begin{array}{l}\text { Possible use only in patients with severe psy- } \\
\text { chiatric comorbidities; lacking data and evi- } \\
\text { dence about efficacy and safety in irritable bowel } \\
\text { syndrome }\end{array}$ \\
\hline
\end{tabular}

SSRIs: selective serotonin reuptake inhibitors. TCADs: trycyclic antidepresants. SNRIs: serotonin norepinephrine reuptake inhibitors. 5-HT: 5hydroxytriptamine.

TABLE 2: Novel psychotropic agents used for the treatment of irritable bowel syndrome.

\begin{tabular}{lll}
\hline Classes of drugs & Mechanism of action & Therapeutic issues \\
\hline $\begin{array}{l}\text { Corticotrophin releasing factor antagonists } \\
\text { Opioidergic agents }\end{array}$ & $\begin{array}{l}\text { Modulation of corticoid system } \\
\text { Modulation of visceral nociception } \\
\text { Cholecystokinin receptor antagonists }\end{array}$ & $\begin{array}{l}\text { Limited use, under investigation } \\
\text { Limited central side effects, good efficacy }\end{array}$ \\
pomathways of cholecystokinin & Limited use, under investigation \\
Beta-3 adrenergic agonists & Inhibition of rectal sensitivity & Limited use and efficacy, under investigation \\
N-methyl-D-aspartate antagonists & Modulation of beta-3 adrenergic system & $\begin{array}{l}\text { Limited efficacy in bowel symptoms } \\
\text { Limited efficacy, restricted on abdominal } \\
\text { pain }\end{array}$ \\
\hline
\end{tabular}

settings, and then to test them in well-designed clinical trials [92].

CBT is considered the most well-studied psychological treatment for IBS [93], but one limitation is that CBT is rarely available in routine care of IBS [94]. Several factors contribute to this, for example, the lack of trained therapists, high costs of delivering the treatment, and the practical difficulties for patients of scheduling weekly visits at a clinic. Interestingly, several researchers have conducted studies investigating CBT for IBS where participants had therapist contact via the internet (ICBT), defined as a web-based bibliotherapy with an online therapist contact: ICBT proved to be a promising cost-effective treatment modality for IBS as it can be offered to IBS patients on a much larger scale than conventional psychological treatments [95].

In the setting of CBT, a study performed by Lackner and coworkers sought to determine whether the therapeutic phenomenon of rapid response characterizes patients undergoing CBT for IBS; in this study, performed on 71 patients, 30\% of CBT-treated patients achieved RR by week 4 of treatment and $90-95 \%$ of patients with rapid response maintained gains at immediate and 3 month followup. The authors concluded that rapid response is a potentially important prognostic outcome indicator that has important implications for developing step care approaches for IBS patients [96].

Another study, performed by Reme and coworkers, wanted to examine predictors of treatment outcome after CBT and antispasmodic treatment for patients with IBS in primary care at 12 months after treatment ended. In this study, lower levels of psychological distress (anxiety and depression) at baseline predicted a good outcome in the mebeverine group, but not in the mebeverine + CBT group; in the adjusted model for the mebeverine + CBT group less adaptive IBS related behavioral coping predicted a good outcome [97].

With regard to hypnosis, an important observation has been made by researchers working on its role in treating IBS [98]. Tan et al. and Wilson et al., respectively, observed in their systematic reviews (in spite of both comprising uncontrolled trials) that hypnotherapy was effective in the management of IBS; however, these authors also recommended better quality trials $[99,100]$.

A Cochrane review and meta-analysis, including four studies, suggests a beneficial effect of hypnosis in the short term, although this result needs to be interpreted with caution, due to the small size and methodological flaws of the studies included, but emphasizes that hypnotherapy appears to be a safe intervention that could be tried in patients who fail standard medical therapy [101].

Curiously, the IMAGINE study [102] showed that if hypnotherapy is effective and if there is no difference in efficacy between individual and group hypnotherapy, this group form of treatment could be offered to more IBS patients, at lower costs.

Another interesting study performed by Lindfors and coworkers showed how gut-directed hypnotherapy is an effective treatment alternative for patients with refractory IBS, but the effectiveness is lower when therapy is given outside highly specialized research centers [103].

With regard to the evidence about psychodynamic therapy, one central problem of all psychodynamic therapy interventions is their poor controllability, as they are different from CBT trials: they are not made up of identifiable 
modules that can be controlled, for example, by dismissing them in the control group, and finally it is less well standardized in terms of its performance (duration, setting) [104]. In a recent systematic review, only two large-scale psychodynamic therapy interventions yielded an odds ratio of $2.92(1.76-4.83)$ [105].

Similarly, few data are available about meditation and reflexology. In a small pilot study performed on 16 patients on whom a medication program was tested and who were asked to practice it regularly at home, a significant improvement was seen in flatulence, bloating, and diarrhea, and clinical responses were sustained with continued meditation at 1-year followup [106]; however, it is unclear whether these results demonstrate a genuine therapeutic effect or a placebo effect. With regard to reflexology, only a small singleblind trial has been conducted, involving 34 IBS patients, in a primary care setting, randomized either to a reflexology foot massage or to a nonreflexology foot massage control group; no significant difference was seen in bowel symptoms between the groups [107].

To date, it is not yet clear if psychosocial therapies are more effective than psychotropic agents in the management of IBS; although some researchers claim the superiority of psychological treatments over antidepressants in terms of long-term reduction in health-care costs [108], there is a scarcity of studies comparing the two different treatment modalities of IBS.

\section{Conclusions}

IBS is a chronic relapsing condition, sometimes associated with significant disability, and with a considerable financial burden for the health service, due to the consumption of resources including physician time, investigations, and costs of treatment [6]. The presence of clinically significant psychiatric symptoms in patients with IBS is an indication for psychotropic agents, especially when stress reactivity is observed [45]. Indeed, antidepressants are effective treatments in IBS, probably as a result of their antinociceptive effects, although additional effects on GI transit may be contributory [6]. Whether any beneficial effect occurs via the treatment of coexistent depression remains unclear, but there was no correlation between depression scores and improvements in IBS symptoms in the studies identified in the meta-analyses that examined this issue [47], also considering that, in the case of TCADs, the doses employed for treating IBS were generally much lower than those used for the treatment of depression [6].

The paucity of data available on the safety and tolerability of psychotropic agents in IBS limits their usage to second-line therapy, according to current IBS management guidelines [48, 109], thus, confirmation of existing practices with randomized, controlled trials is strongly needed.

With regard to psychological therapies, it is not yet clear if they are more effective than psychotropic agents in the management of IBS. The present evidence show that psychological therapies may be superior to the usual care at the end of treatment, although the clinical significance of this benefit is doubtful and the long-term sustainability of the effects of these treatments is questionable; further studies should focus on the longer term effects and placebos, following current recommendations for IBS treatment trials.

\section{Conflict of Interests}

The authors declare that they have no conflict of interests.

\section{References}

[1] P. M. Boyce, N. A. Koloski, and N. J. Talley, "Irritable bowel syndrome according to varying diagnostic criteria: are the new Rome II criteria unnecessarily restrictive for research and practice?" American Journal of Gastroenterology, vol. 95, no. 11 , pp. 3176-3183, 2000.

[2] M. T. Hillilä and M. A. Färkkilä, "Prevalence of irritable bowel syndrome according to different diagnostic criteria in a non-selected adult population," Alimentary Pharmacology and Therapeutics, vol. 20, no. 3, pp. 339-345, 2004.

[3] A. P. S. Hungin, P. J. Whorwell, J. Tack, and F. Mearin, “The prevalence, patterns and impact of irritable bowel syndrome: an international survey of 40000 subjects," Alimentary Pharmacology and Therapeutics, vol. 17, no. 5, pp. 643-650, 2003.

[4] F. Mearin, X. Badía, A. Balboa et al., "Irritable bowel syndrome prevalence varies enormously depending on the employed diagnostic criteria: comparison of Rome II versus previous criteria in a general population," Scandinavian Journal of Gastroenterology, vol. 36, no. 11, pp. 1155-1161, 2001.

[5] R. F. Harvey, S. Y. Salih, and A. E. Read, "Organic and functional disorders in 2000 gastroenterology outpatients," The Lancet, vol. 1, no. 8325, pp. 632-634, 1983.

[6] A. Sainsbury and A. C. Ford, "Review: treatment of irritable bowel syndrome: beyond fiber and antispasmodic agents," Therapeutic Advances in Gastroenterology, vol. 4, no. 2, pp. 115-127, 2011.

[7] G. F. Longstreth, W. G. Thompson, W. D. Chey, L. A. Houghton, F. Mearin, and R. C. Spiller, "Functional bowel disorders," Gastroenterology, vol. 130, no. 5, pp. 1480-1491, 2006.

[8] T. Surdea-Blaga, A. Baban, and D. L. Dumitrascu, "Psychosocial determinants of irritable bowel syndrome," World Journal of Gastroenterology, vol. 18, no. 7, pp. 616-626, 2012.

[9] G. F. Longstreth, W. G. Thompson, W. D. Chey, L. A. Houghton, F. Mearin, and R. C. Spiller, "Functional bowel disorders," in Rome III: The Functional Gastrointestinal Disorders, D. A. Drossman, E. Corazziari, M. Delvaux et al., Eds., pp. 487-555, Degnon Associates, McLean, Va, USA, 3rd edition, 2006.

[10] D. A. Drossman, "Presidential address: gastrointestinal illness and the biopsychosocial model," Psychosomatic Medicine, vol. 60, no. 3, pp. 258-267, 1998.

[11] D. A. Drossman, "The functional gastrointestinal disorders and the Rome III process," in Rome III: The Functional Gastrointestinal Disorders, D. A. Drossman, E. Corazziari, M. Delvaux et al., Eds., pp. 1-30, Degnon Associates, McLean, Va, USA, 3rd edition, 2006.

[12] D. A. Drossman, "The functional gastrointestinal disorders and the Rome III process," Gastroenterology, vol. 130, no. 5, pp. 1377-1390, 2006. 
[13] G. Richard Locke, A. R. Zinsmeister, N. J. Talley, S. L. Fett, and L. Joseph Melton, "Familial association in adults with functional gastrointestinal disorders," Mayo Clinic Proceedings, vol. 75, no. 9, pp. 907-912, 2000.

[14] M. Aguas, V. Garrigues, G. Bastida, P. Nos, V. Ortiz, and J. Ponce, "Prevalence of irritable bowel syndrome in firstdegree relatives of patients with inflammatory bowel disease. Quality of life and economic impact," Gastroenterology, vol. 138, supplement 1, no. 5, p. S627, 2010.

[15] T. E. Senn, M. P. Carey, and P. A. Vanable, "Childhood and adolescent sexual abuse and subsequent sexual risk behavior: evidence from controlled studies, methodological critique, and suggestions for research," Clinical Psychology Review, vol. 28, no. 5, pp. 711-735, 2008.

[16] N. J. Talley, S. L. Fett, A. R. Zinsmeister, and L. J. Melton, "Gastrointestinal tract symptoms and self-reported abuse: a population- based study," Gastroenterology, vol. 107, no. 4, pp. 1040-1049, 1994.

[17] C. Han, P. S. Masand, S. Krulewicz et al., "Childhood abuse and treatment response in patients with irritable bowel syndrome: a post-hoc analysis of a 12-week, randomized, double-blind, placebo-controlled trial of paroxetine controlled release," Journal of Clinical Pharmacy and Therapeutics, vol. 34, no. 1, pp. 79-88, 2009.

[18] D. A. Drossman, J. Leserman, G. Nachman et al., "Sexual and physical abuse in women with functional or organic gastrointestinal disorders," Annals of Internal Medicine, vol. 113, no. 11, pp. 828-833, 1990.

[19] D. L. Dumitrascu, M. Stanculete, S. Costin, and D. Dumitrascu, "Geographical differences in the report of sexual abuse in females with irritable bowel syndrome," in Proceedings of the 19th World Congress on Psychosomatic Medicine, Québec, Canada, August 2007.

[20] H. Beesley, J. Rhodes, and P. Salmon, "Anger and childhood sexual abuse are independently associated with irritable bowel syndrome," British Journal of Health Psychology, vol. 15, no. 2, pp. 389-399, 2010.

[21] N. A. Koloski, N. J. Talley, and P. M. Boyce, "A history of abuse in community subjects with irritable bowel syndrome and functional dyspepsia: the role of other psychosocial variables," Digestion, vol. 72, no. 2-3, pp. 86-96, 2005.

[22] P. T. Costa and R. R. McCrae, NEO PI-R Professional Manual (Revised NEO Personality Inventory and NEO Five-Factor Inventory), Psychological Assessment Resources, Odessa, Ukraine, 1992.

[23] T. Chamorro-Premuzic, Personality and Individual Differences, Blackwell Publishing, Malden, Mass, USA, 2007.

[24] P. E. Sifneos, "Alexithymia: past and present," American Journal of Psychiatry, vol. 153, no. 7, pp. 137-142, 1996.

[25] G. J. Taylor and H. S. Taylor, "Alexithymia," in Psychological Mindedness: A Contemporary Understanding, M. McCallum and W. E. Piper, Eds., Personality \& Clinical Psychology, Lawrence Erlbaum Associates, Munich, Germany, 1997.

[26] R. S. Lazarus and S. Folkman, Stress, Appraisal and Coping, Springer, New York, NY, USA, 1984.

[27] D. A. Drossman, L. Chang, S. Schneck, C. Blackman, W. F. Norton, and N. J. Norton, "A focus group assessment of patient perspectives on irritable bowel syndrome and illness severity," Digestive Diseases and Sciences, vol. 54, no. 7, pp. 1532-1541, 2009.

[28] T. A. Widiger and A. Thomas, Eds., Diagnosis and Statistical Manual of Mental Disorders, American Psychatric Publishing, Washington, DC, USA, 4th edition, 1994.
[29] F. H. Creed, R. Levy, L. Bradley et al., "Psychosocial aspects of functional gastrointestinal disorders," in Rome III: The Functional Gastrointestinal Disorders, D. A. Drossman, E. Corazzieri, M. Delvaux et al., Eds., pp. 295-368, Degnon Associates, McLean, Va, USA, 3rd edition, 2006.

[30] F. Creed, J. Ratcliffe, L. Fernandes et al., "Outcome in severe irritable bowel syndrome with and without accompanying depressive, panic and neurasthenic disorders," British Journal of Psychiatry, vol. 186, pp. 507-515, 2005.

[31] W. E. Whitehead, O. S. Palsson, R. L. Levy, M. Von Korff, A. D. Feld, and M. J. Turner, "Comorbid psychiatric disorders in irritable bowel (IBS) and inflammatory bowel disease (IBD)," Gastroenterology, vol. 124, article A398, 2003.

[32] P. Henningsen, T. Zimmermann, and H. Sattel, "Medically unexplained physical symptoms, anxiety, and depression: a meta-analytic review," Psychosomatic Medicine, vol. 65, no. 4, pp. 528-533, 2003.

[33] A. R. Miller, C. S. North, R. E. Clouse, R. D. Wetzel, E. L. Spitznagel, and D. H. Alpers, "The association of irritable bowel syndrome and somatization disorder," Annals of Clinical Psychiatry, vol. 13, no. 1, pp. 25-30, 2001.

[34] C. S. North, D. Downs, R. E. Clouse et al., "The presentation of irritable bowel syndrome in the context of somatization disorder," Clinical Gastroenterology and Hepatology, vol. 2, no. 9, pp. 787-795, 2004.

[35] G. R. Locke, A. L. Weaver, L. J. Melton, and N. J. Talley, "Psychosocial factors are linked to functional gastrointestinal Disorders: a population based nested case-control study," American Journal of Gastroenterology, vol. 99, no. 2, pp. 350357, 2004.

[36] N. J. Talley, E. H. Dennis, V. A. Schettler-Duncan, B. E. Lacy, K. W. Olden, and M. D. Crowell, "Overlapping upper and lower gastrointestinal symptoms in irritable bowel syndrome patients with constipation or diarrhea," American Journal of Gastroenterology, vol. 98, no. 11, pp. 2454-2459, 2003.

[37] S. L. S. Halder, G. R. Locke, N. J. Talley, S. L. Fett, A. R. Zinsmeister, and L. J. Melton, "Impact of functional gastrointestinal disorders on health-related quality of life: a population-based case-control study," Alimentary Pharmacology and Therapeutics, vol. 19, no. 2, pp. 233-242, 2004.

[38] G. Holtmann, S. U. Kutscher, S. Haag et al., "Clinical presentation and personality factors are predictors of the response to treatment in patients with functional dyspepsia: a randomized, double-blind placebo-controlled crossover study," Digestive Diseases and Sciences, vol. 49, no. 4, pp. 672679, 2004.

[39] M. P. Jones, J. B. Dilley, D. Drossman, and M. D. Crowell, "Brain-gut connections in functional GI disorders: anatomic and physiologic relationships," Neurogastroenterology and Motility, vol. 18, no. 2, pp. 91-103, 2006.

[40] S. J. Eisendrath and K. T. Kodama, "Fluoxetine management of chronic abdominal pain," Psychosomatics, vol. 33, no. 2, pp. 227-229, 1992.

[41] S. R. Hameroff, J. L. Weiss, and J. C. Lerman, "Doxepin's effects on chronic pain and depression: a controlled study," Journal of Clinical Psychiatry, vol. 45, no. 3, pp. 47-52, 1984.

[42] I. Pilowsky and C. G. Barrow, "A controlled study of psychotherapy and amitriptyline used individually and in combination in the treatment of chronic intractable, 'psychogenic' pain," Pain, vol. 40, no. 1, pp. 3-19, 1990.

[43] D. A. Gorard, G. W. Libby, and M. J. G. Farthing, "Effect of a tricyclic antidepressant on small intestinal motility in health and diarrhea-predominant irritable bowel syndrome," Digestive Diseases and Sciences, vol. 40, no. 1, pp. 86-95, 1995. 
[44] A. G. Gilman, J. G. Hardman, and L. E. Limbird, Goodman \& Gilman'S the Pharmacological Basis of Therapeutics, McGrawHill, New York, NY, USA, 10th edition, 2001.

[45] M. Camilleri, L. Bueno, F. de Ponti, J. Fioramonti, R. B. Lydiard, and J. Tack, "Pharmacological and pharmacokinetic aspects of functional gastrointestinal disorders," Gastroenterology, vol. 130, no. 5, pp. 1421-1434, 2006.

[46] D. A. Drossman and W. G. Thompson, "The irritable bowel syndrome: review and a graduated multicomponent treatment approach," Annals of Internal Medicine, vol. 116, no. 12, pp. 1009-1016, 1992.

[47] A. C. Ford, N. J. Talley, P. S. Schoenfeld, E. M. M. Quigley, and P. Moayyedi, "Efficacy of antidepressants and psychological therapies in irritable bowel syndrome: systematic review and meta-analysis," Gut, vol. 58, no. 3, pp. 367-378, 2009.

[48] American College of Gastroenterology Task Force on Irritable Bowel Syndrome, L. J. Brandt, W. D. Chey et al., "An evidence-based position statement on the management of irritable bowel syndrome," The American Journal of Gastroenterology, vol. 104, supplement 1, pp. S1-S35, 2009.

[49] H. Abdul-Baki, I. I. El Hajj, L. Elzahabi et al., "A randomized controlled trial of imipramine in patients with irritable bowel syndrome," World Journal of Gastroenterology, vol. 15, no. 29, pp. 3636-3642, 2009.

[50] P. S. Masand, C. U. Pae, S. Krulewicz et al., "A doubleblind, randomized, placebo-controlled trial of paroxetine controlled-release in irritable bowel syndrome," Psychosomatics, vol. 50, no. 1, pp. 78-86, 2009.

[51] U. Ladabaum, A. Sharabidze, T. R. Levin et al., "Citalopram provides little or no benefit in nondepressed patients with irritable bowel syndrome," Clinical Gastroenterology and Hepatology, vol. 8, no. 1, pp. 42-48, 2010.

[52] A. C. Ford and P. Moayyedi, "'Power" of selective serotonin reuptake inhibitors in irritable bowel syndrome," Clinical Gastroenterology and Hepatology, vol. 8, no. 3, pp. 313-314, 2010.

[53] K. Yamaguchi, K. Suzuki, and T. Niho, “Tofisopam, a new 2,3-benzodiazepine. Inhibition of changes induced by stress loading and hypothalamic stimulation," Canadian Journal of Physiology and Pharmacology, vol. 61, no. 6, pp. 619-625, 1983.

[54] R. B. Lydiard, "Psychopharmacology in the treatment of irritable bowel syndrome," Primary Psychiatry, vol. 14, no. 4, pp. 40-50, 2007.

[55] M. Saps, N. Youssef, A. Miranda et al., "Multicenter, randomized, placebo-controlled trial of amitriptyline in children with functional gastrointestinal disorders," Gastroenterology, vol. 137, no. 4, pp. 1261-1269, 2009.

[56] R. J. Bahar, B. S. Collins, B. Steinmetz, and M. E. Ament, "Double-blind placebo-controlled trial of amitriptyline for the treatment of irritable bowel syndrome in adolescents," Journal of Pediatrics, vol. 152, no. 5, pp. 685-689, 2008.

[57] A. Kaminski, A. Kamper, K. Thaler, A. Chapman, and G. Gartlehner, "Antidepressants for the treatment of abdominal pain-related functional gastrointestinal disorders in children and adolescents," Cochrane Database of Systematic Reviews, no. 7, Article ID CD008013, 2011.

[58] M. Camilleri, "Pharmacology of the new treatments for lower gastrointestinal motility disorders and irritable bowel syndrome," Clinical Pharmacology and Therapeutics, vol. 91, no. 1, pp. 44-59, 2012.

[59] M. Grover, S. D. Dorn, S. R. Weinland, C. B. Dalton, B. N. Gaynes, and D. A. Drossman, "Atypical antipsychotic quetiapine in the management of severe refractory functional gastrointestinal disorders," Digestive Diseases and Sciences, vol. 54, no. 6, pp. 1284-1291, 2009.

[60] P. Iovino, F. Azpiroz, E. Domingo, and J. R. Malagelada, "The sympathetic nervous system modulates perception and reflex responses to gut distention in humans," Gastroenterology, vol. 108, no. 3, pp. 680-686, 1995.

[61] E. J. Horvath, K. Horvath, T. Hamori, M. I. Fekete et al., "Anxyolitic 2, 3-benzodiazepines, their specific binding to the basal ganglia," Progress in Neurobiology, vol. 60, pp. 309-342, 2000.

[62] S. M. Leventer, R. F. Kucharik, J. C. Keogh, M. Karen et al., "The potential of dextofisopam for treatment of irritable bowel syndrome and inflammatory bowel disease," The American Journal of Gastroenterology, vol. 99, p. S279, 2004.

[63] S. M. Leventer, K. Raudibaugh, C. L. Frissora et al., "Clinical trial: dextofisopam in the treatment of patients with diarrhoea-predominant or alternating irritable bowel syndrome," Alimentary Pharmacology and Therapeutics, vol. 27, no. 2, pp. 197-206, 2008.

[64] K. W. Olden, "The use of antidepressants in functional gastrointestinal disorders: new uses for old drugs," CNS Spectrums, vol. 10, no. 11, pp. 891-896, 2005.

[65] M. Castedal, E. Björnsson, and H. Abrahamsson, "Effects of midazolam on small bowel motility in humans," Alimentary Pharmacology and Therapeutics, vol. 14, no. 5, pp. 571-577, 2000.

[66] M. Larauche, A. Mulak, and Y. Taché, "Stress and visceral pain: from animal models to clinical therapies," Experimental Neurology, vol. 233, no. 1, pp. 49-67, 2012.

[67] L. A. Houghton, C. Fell, P. J. Whorwell, I. Jones, D. P. Sudworth, and J. D. Gale, "Effect of a second-generation $\alpha 2 \delta$ ligand (pregabalin) on visceral sensation in hypersensitive patients with irritable bowel syndrome," Gut, vol. 56, no. 9, pp. 1218-1225, 2007.

[68] K. J. Lee, J. H. Kim, and S. W. Cho, "Gabapentin reduces rectal mechanosensitivity and increases rectal compliance in patients with diarrhoea-predominant irritable bowel syndrome," Alimentary Pharmacology and Therapeutics, vol. 22, no. 10, pp. 981-988, 2005.

[69] M. Delvaux, D. Louvel, E. Lagier, B. Scherrer, J. L. Abitbol, and J. Frexinos, "The $\kappa$ agonist fedotozine relieves hypersensitivity to colonic distention in patients with irritable bowel syndrome," Gastroenterology, vol. 116, no. 1, pp. 38-45, 1999.

[70] M. Delvaux, A. Beck, J. Jacob, H. Bouzamondo, F. T. Weber, and J. Frexinos, "Effect of asimadoline, a $\kappa$ opioid agonist, on pain induced by colonic distension in patients with irritable bowel syndrome," Alimentary Pharmacology and Therapeutics, vol. 20, no. 2, pp. 237-246, 2004.

[71] A. W. Mangel, J. D. Bornstein, L. R. Hamm et al., "Clinical trial: asimadoline in the treatment of patients with irritable bowel syndrome," Alimentary Pharmacology and Therapeutics, vol. 28, no. 2, pp. 239-249, 2008.

[72] L. A. Szarka, M. Camilleri, D. Burton et al., "Efficacy of on-demand asimadoline, a peripheral $\kappa$-opioid agonist, in females with irritable bowel syndrome," Clinical Gastroenterology and Hepatology, vol. 5, no. 11, pp. 1268-1275, 2007.

[73] S. Cellek, R. Thangiah, A. K. Bassil et al., "Demonstration of functional neuronal $\beta 3$-adrenoceptors within the enteric nervous system," Gastroenterology, vol. 133, no. 1, pp. 175183, 2007.

[74] A. B. M. Grudell, M. Camilleri, K. L. Jensen et al., "Dose-response effect of a $\beta 3$-adrenergic receptor agonist, solabegron, on gastrointestinal transit, bowel function, and 
somatostatin levels in health," American Journal of Physiology, vol. 294, no. 5, pp. G1114-G1119, 2008.

[75] D. L. Kelleher, K. J. Hicks, D. S. Cox, R. R. Williamson, D. H. Alpers, and G. E. Dukes, "Randomized, doubleblind, placebo (PLA) controlled, crossover study to evaluate efficacy and safety of the beta 3-adrenergic receptor agonist solabegron (SOL) in patients with irritable bowel syndrome (IBS)," Neurogastroenterology and Motility, vol. 20, pp. 131132, 2008.

[76] A. B. Petrenko, T. Yamakura, H. Baba, and K. Shimoji, "The role of N-methyl-D-aspartate (NMDA) receptors in pain: a review," Anesthesia and Analgesia, vol. 97, no. 4, pp. 11081116, 2003.

[77] A. Siu and R. Drachtman, "Dextromethorphan: a review of $\mathrm{N}$-methyl-D-aspartate receptor antagonist in the management of pain," CNS Drug Reviews, vol. 13, no. 1, pp. 96-106, 2007.

[78] Q. Zhou, B. Zhang, and G. Nicholas Verne, "Intestinal membrane permeability and hypersensitivity in the irritable bowel syndrome," Pain, vol. 146, no. 1-2, pp. 41-46, 2009.

[79] Q. Zhou, D. D. Price, C. S. Callam, M. A. Woodruff, and G. N. Verne, "Effects of the N-Methyl-D-aspartate receptor on temporal summation of second pain (Wind-up) in irritable bowel syndrome," Journal of Pain, vol. 12, no. 2, pp. 297-303, 2011.

[80] F. Cremonini, M. Camilleri, S. McKinzie et al., "Effect of CCK-1 antagonist, dexloxiglumide, in female patients with irritable bowel syndrome: a pharmacodynamic and pharmacogenomic study," American Journal of Gastroenterology, vol. 100, no. 3, pp. 652-663, 2005.

[81] S. Sweetser, M. Camilleri, S. J. Linker Nord et al., "Do corticotropin releasing factor-1 receptors influence colonic transit and bowel function in women with irritable bowel syndrome?" American Journal of Physiology, vol. 296, no. 6, pp. G1299-G1306, 2009.

[82] T. K. Klooker, S. D. Kuiken, A. Lei, and G. E. Boeckxstaens, "Effect of long-term treatment with octreotide on rectal sensitivity in patients with non-constipated irritable bowel syndrome," Alimentary Pharmacology and Therapeutics, vol. 26, no. 4, pp. 605-615, 2007.

[83] K. L. Whitfield and R. J. Schulman, "Treatment options for functional gastrointestinal disorders: from empiric to complementary approaches," Pediatric Annals, vol. 38, no. 5, pp. 288-294, 2009.

[84] P. J. Whorwell, "Behavioral therapy for IBS," Nature Clinical Practice Gastroenterology \& Hepatology, vol. 6, pp. 148-149, 2009.

[85] E. B. Banchard, J. M. Lackner, K. Sanders et al., "A controller evaluation of group cognitive therapy in the treatment of irritable bowel syndrome," Behaviour Research and Therapy, vol. 45, pp. 633-648, 2007.

[86] B. Bursch, "Psychological/cognitive behavioral treatment of childhood functional abdominal pain and irritable bowel syndrome," Journal of Pediatric Gastroenterology and Nutrition, vol. 47, no. 5, pp. 706-707, 2008.

[87] G. F. Koob and S. C. Heinrichs, "A role for corticotropin releasing factor and urocortin in behavioral responses to stressors," Brain Research, vol. 848, no. 1-2, pp. 141-152, 1999.

[88] S. Evangelista, "Benefits from long-term treatment in irritable bowel syndrome," Gastroenterology Research and Practice, vol. 2012, Article ID 936960, 6 pages, 2012.
[89] J. Svedlund, I. Sjodin, J. Ottosson, and G. Dotevall, "Controlled study of psychotherapy in irritable bowel syndrome," The Lancet, vol. 2, no. 8350, pp. 589-592, 1983.

[90] I. L. Zijdenbos, N. J. de Wit, G. J. van der Heijden, G. Rubin, and A. O. Quartero, "Psychological treatments for the management of irritable bowel syndrome," Cochrane Database of Systematic Reviews, no. 1, Article ID CD006442, 2009.

[91] J. M. Lackner, J. Jaccard, S. S. Krasner, L. A. Katz, G. D. Gudleski, and E. B. Blanchard, "How does cognitive behavior therapy for irritable bowel syndrome work? A Mediational Analysis of a Randomized Clinical Trial," Gastroenterology, vol. 133, no. 2, pp. 433-444, 2007.

[92] S. D. Dorn, "Systematic review: self-management support interventions for irritable bowel syndrome," Alimentary Pharmacology and Therapeutics, vol. 32, no. 4, pp. 513-521, 2010.

[93] E. A. Mayer, "Irritable bowel syndrome," New England Journal of Medicine, vol. 358, no. 16, pp. 1692-1699, 2008.

[94] A. P. S. Hungin, "Self-help interventions in irritable bowel syndrome," Gut, vol. 55, no. 5, pp. 603-604, 2006.

[95] B. Ljòttson, G. Andersson, E. Andersson, E. Hedman, P. Lindfors, S. Andrèewitch et al., "Acceptability, effectiveness, and cost-effectiveness of internet-based exposure treatment for irritable bowel syndrome in a clinical sample: a randomized controlled trial," BMC Gastroenterology, vol. 11, no. 110, pp. 1-13, 2011.

[96] J. M. Lackner, G. D. Gudleski, L. Keefer, S. S. Krasner, C. Powell, and L. A. Katz, "Rapid response to cognitive behavior therapy predicts treatment outcome in patients with irritable bowel syndrome," Clinical Gastroenterology and Hepatology, vol. 8, no. 5, pp. 426-432, 2010.

[97] S. E. Reme, T. Kennedy, R. Jones, S. Darnley, and T. Chalder, "Predictors of treatment outcome after cognitive behavior therapy and antispasmodic treatment for patients with irritable bowel syndrome in primary care," Journal of Psychosomatic Research, vol. 68, no. 4, pp. 385-388, 2010.

[98] A. Micocka-Walus, "Treatment of psychosocial comorbidities in comm on Gastrointestinal and hepatologic disorders," World Journal of Gastrointestinal Pharmacology and Therapeutics, vol. 1, no. 2, pp. 64-71, 2010.

[99] G. Tan, D. C. Hammond, and J. Gurrala, "Hypnosis and irritable bowel syndrome: a review of efficacy and mechanism of action," American Journal of Clinical Hypnosis, vol. 47, no. 3, pp. 161-178, 2005.

[100] S. Wilson, T. Maddison, L. Roberts, S. Greenfield, and S. Singh, "Systematic review: the effectiveness of hypnotherapy in the management of irritable bowel syndrome," Alimentary Pharmacology and Therapeutics, vol. 24, no. 5, pp. 769-780, 2006.

[101] A. N. Webb, R. H. Kukuruzovic, A. G. Catto-Smith, and S. M. Sawyer, "Hypnotherapy for treatment of irritable bowel syndrome," Cochrane Database of Systematic Reviews, no. 4, Article ID CD005110, 2007.

[102] C. E. Flick, Y. R. van Rood, W. Laan et al., "A randomized controlled trial on hypnotherapy for irritable bowel syndrome: design and methodological challenges (the IMAGINE study)," BMC Gastroenterology, vol. 11, no. 137, pp. 1-10, 2011.

[103] P. Lindfors, P. Unge, P. Arvidsson, H. Nyhlin, E. Bjornsson, H. Abrahammson et al., "Effects of gut-directed hypnotherapy on IBS in different clinical settings-results from two 
randomized, controlled trials," The American Journal of Gastroenterology, vol. 107, no. 2, pp. 276-285, 2012.

[104] F. Creed and E. Guthrie, "Psychological treatments of the irritable bowel syndrome: a review," Gut, vol. 30, no. 11, pp. 1601-1609, 1989.

[105] P. Enck, F. Junne, S. Klosterhalfen, S. Zipfel, and U. Martens, "Therapy options in irritable bowel syndrome," European Journal of Gastroenterology and Hepatology, vol. 22, no. 12, pp. 1402-1411, 2010.

[106] L. Keefer and E. B. Blanchard, "A one year follow-up of relaxation response meditation as a treatment for irritable bowel syndrome," Behaviour Research and Therapy, vol. 40, no. 5, pp. 541-546, 2002.

[107] P. A. Tovey, "A single-blind trial of reflexology for irritable bowel syndrome," British Journal of General Practice, vol. 52, no. 474, pp. 19-23, 2002.

[108] F. Creed, L. Fernandes, E. Guthrie et al., "The costeffectiveness of psychotherapy and paroxetine for severe irritable bowel syndrome," Gastroenterology, vol. 124, no. 2, pp. 303-317, 2003.

[109] R. Spiller, Q. Aziz, and F. Creed, "Guidelines on the irritable bowel syndrome: mechanisms and practical management," Gut, vol. 56, pp. 1770-1798, 2007. 


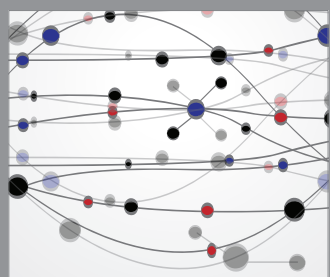

The Scientific World Journal
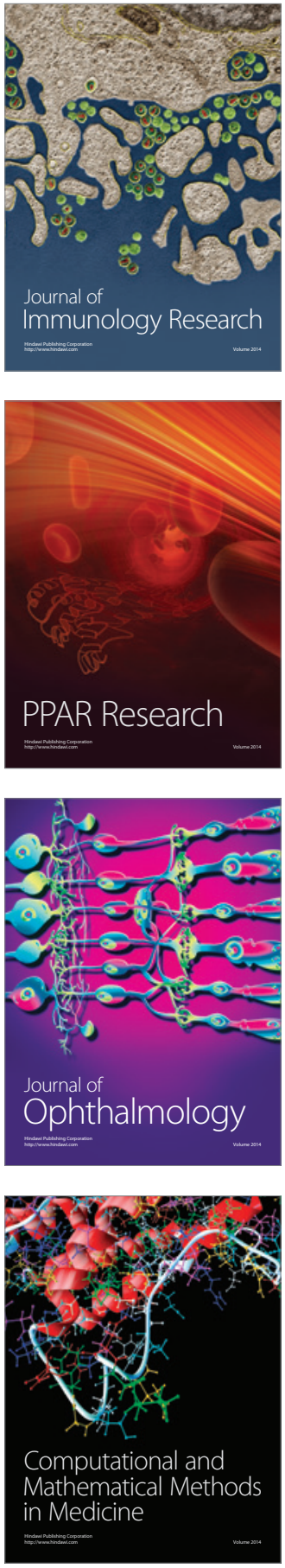

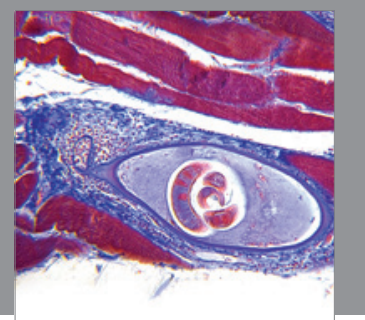

Gastroenterology

Research and Practice
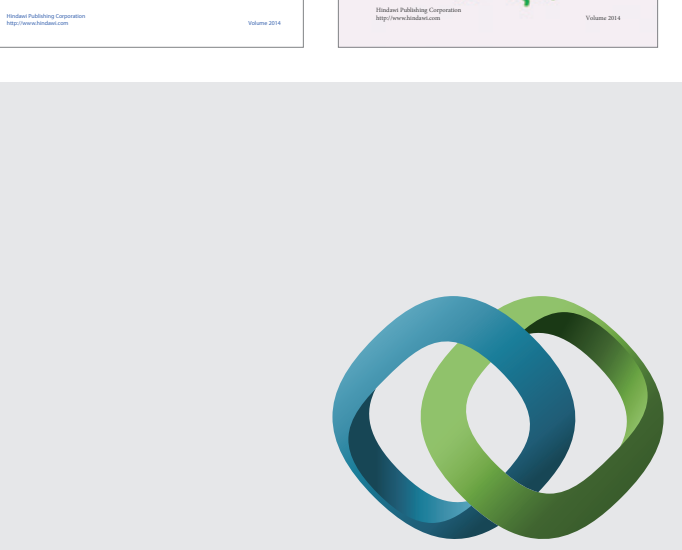

\section{Hindawi}

Submit your manuscripts at

http://www.hindawi.com
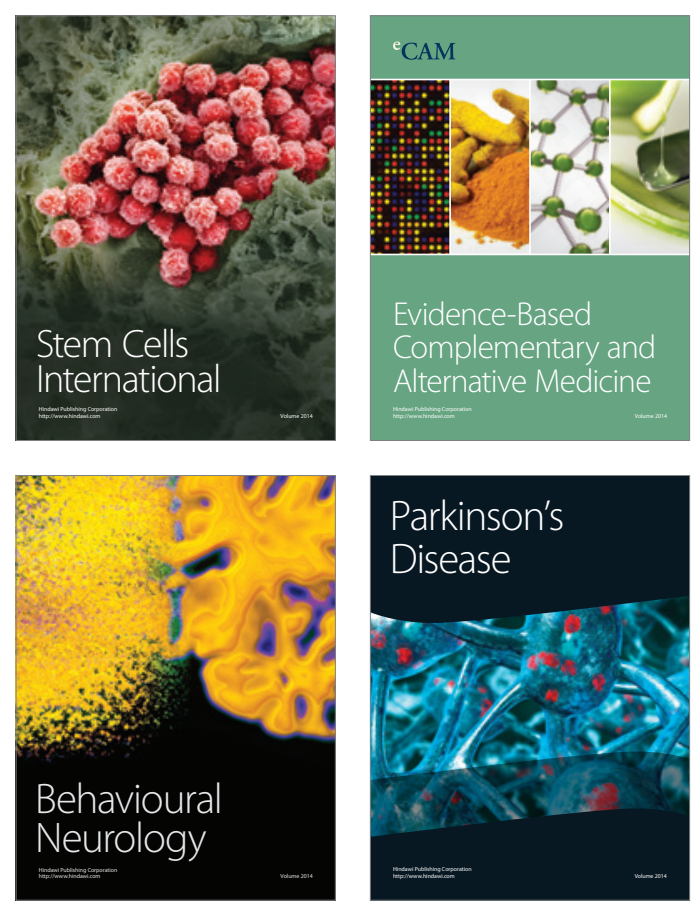

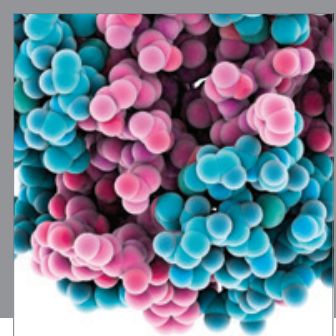

Journal of
Diabetes Research

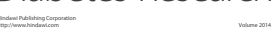

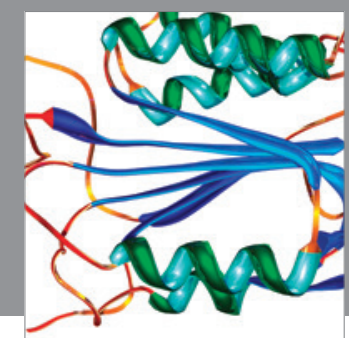

Disease Markers
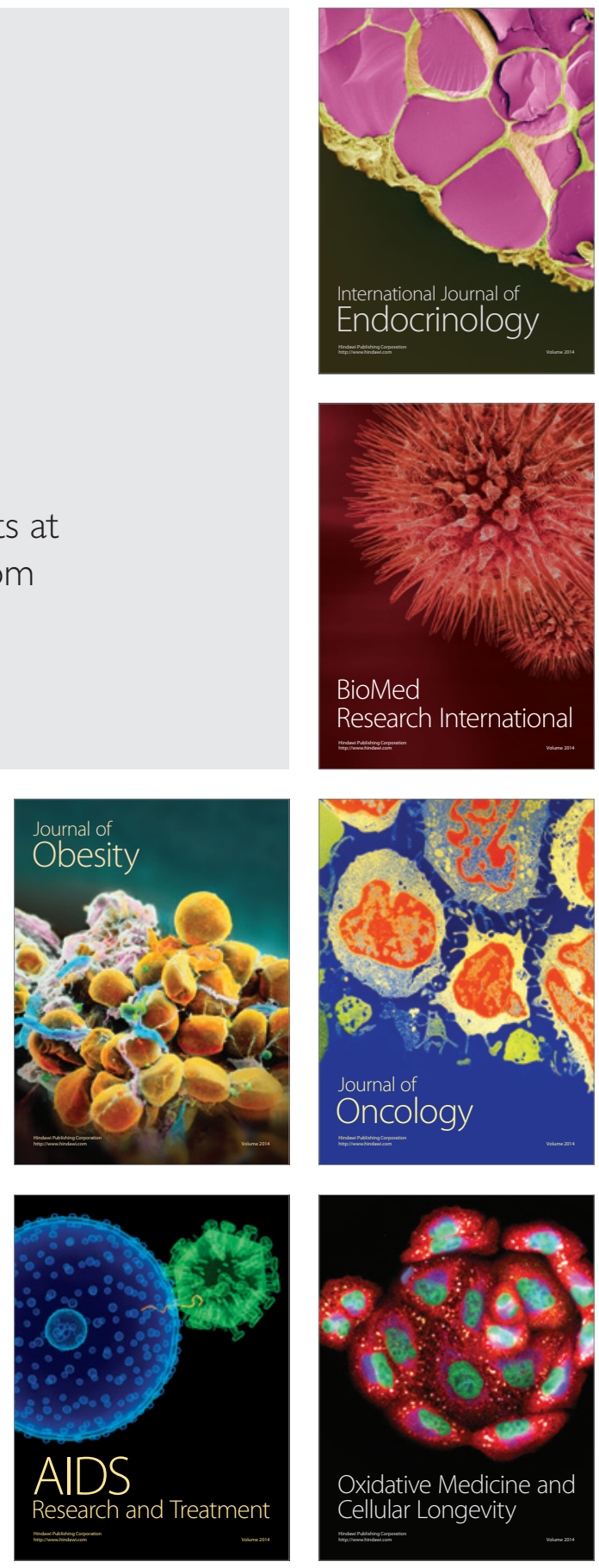